\title{
Market Concentration and Its Relevance in Pharmaceutical Health Care Access in Rural Communities in Nigeria
}

\author{
Usar IJ* Akosu JI \\ Department of Community Health, College of Health Sciences, University of Jos, Nigeria
}

\begin{abstract}
Background: Universal Health Coverage (UHC) of populations is now a key objective of global health systems. UHC seeks to provide equitable access to essential health care for all who need health care without financial hardship. Unfortunately, the $21^{\text {st }}$ century has rolled off with the majority of Nigerians still unable to have adequate access to affordable essential medicines for preventing, mitigating or curing diseases from formal sources, particularly in rural communities. In these settings, informal pharmaceutical entrepreneurs (called patent medicine vendors) are often the sole sources of modern medicines and sometimes double as prescribers as well. There are a number of studies about these entrepreneurs, but none that examines the market structure. The study seeks to gain insight into the structure and conduct of this market in order to improve its performance. Method: A crosssectional, mixed method design based on the structure-conduct-performance (S-C-P) paradigm was used to collect quantitative and qualitative data from patent medicine vendor operators and clients in Kastina-Ala local government council of Benue State, Nigeria. Quantitative data was analyzed using statistical package for social sciences (SPSS) version 20.0, while qualitative data was manually analyzed guided by aproiri themes.Findings: Sellers in the market were small sized, selling branded and generic drugs, with none capable of price leadership. There were low entry barriers, with an overall inverse HHI of 0.01 and a shop per capita of 1:2,669 populations, signifying inadequate access to essential medicines,Conclusion: We conclude that focusing on market concentration as a marker of market efficiency may not always result in the socially desirable health system goal of adequate access to care. Greater emphasis should be placed on developing new health care market policy frameworks that embed both competition and access dimensions in guiding health care market operations.
\end{abstract}

Keywords: Pharmaceuticals; Market concentration; Health care access; Rural communities; Nigeria

DOI: $10.7176 / \mathrm{JESD} / 10-14-10$

Publication date:July $31^{\text {st }} 2020$

\section{Introduction}

Universal Health Coverage (UHC) of populations is now the key focus of global health systems, as countries strive to provide equitable access to essential health care, without financial hardship (WHO 2014; UN 2019). Access to healthcare services impact population health, which in turn influences productivity of individuals and communities, and ultimately sustainable development. At the heart of UHC is access to essential medicines, given that pharmaceuticals play important roles in improving population healthcare outcomes (UN 2000; 2019). Essential medicines are drugs that meet the healthcare needs of the majority of people, and are available in adequate quantities, in appropriate dosage forms, at all times and at affordable prices to individuals and communities (WHO 2013). Unfortunately, the $21^{\text {st }}$ century has rolled off with the majority of Nigerians still having inadequate, or no access to affordable essential medicines for preventing, mitigating or curing diseases from public facilites (UNCTAD 2015). The constrained access is most acute in rural areas where over $60 \%$ of the population resides (Usar et al. 2017; National Population Commission 2006). In rural settings, informal pharmaceutical entrepreneurs (called patent medicine vendors) are often the sole sources of modern medicines and may double as prescribers (Salako et al. 2001; Oladepo et al. 2007). These pharmaceutical entrepreneurs play important roles in the supply of pharmaceutical products and services, both in terms of market share and population coverage with essential medicines. For example, patent medicine vendors alone may account for about $70 \%$ of all malarial treatments in Nigeria (ACTwatch 2013). There is thus, a growing interest in the patent medicine vendor market in Nigeria recently, and a number of studies exploring diverse aspects of this phenomenon exist in the literature (Adilwu 1996; Alubo 2001; Brieger et al. 2004). However, the structure and functioning of this market has not been studied. This study therefore, seeks to understand this market using the structure-conduct-performance (SCP) model and the relevance of market concentration to the attainment of health system goal of improved access to pharmaceuticals in Nigeria.

The SCP model posits that the structure of a firm will determine how the firm will behave in the market, which will in turn determine the market performance (Clarke, 1985). In the model, structural elements refer to number of sellers and buyers, entry and exit barriers, product differentiation and regulatory framework, while conduct components include advertising, pricing, research and development, collusion, mergers and contracts. Market performance may be reflected in prices, profits, product quality, efficiency, equity and technical progress.

Typically, market concentration is used to analyze the number and sizes of sellers in a market and therefore, its competitiveness (Clarke 1985). Concentration is measured in a number of ways such as Gini Coefficient, 
Inverse Index, Entropy (Encaoua and Jacquemin 1980), or simply counting the number of sellers in a market, without regards to their relative market shares. However, the Hirschman-Herfindahl Index (HHI) is the preferred measurement approach and integrates both seller numbers and their market shares (Clarke 1985; Gaynor and Vogt 2000). The index ranges from 0 to 1 , with 0 representing un-concentrated, perfect competition and 1 reflecting concentrated monopoly structure. Generally, increasing HHI indicate decreasing competition and increasing market power and vice versa.

Market entry barriers are factors that enhance profitability of incumbent firms, while disadvantaging new entrants and may include cost advantages, product differentiation, economies of scale and regulatory requirements (Djankov 2002). Product information characteristics enable consumers judge the quality of products in a market, and in healthcare, has significant implications for competition particularly, where consumers are not able to observe quality and become less responsive to quality signals. This often results in market failure (Nelson 1970). Public regulation of markets focuses on improving market performance and consumer protection. The range of market regulatory mechanisms may include entry and exit requirements, product standards, price controls, process guidelines, codes of conduct, subsidies, taxes and accreditations. The impact of regulation on market competitiveness depends on market structure, provider conduct and enforcement capacity.

Provider conduct refers to the activities sellers undertake to influence market events and outcomes, and include price fixing, product differentiation, regulatory compliance and collusion. In high concentrated markets, sellers deploy entry restrictions, information asymmetry and collusion to exercise price sovereignty, which may be based on rule of thumb, mark-ups, or copying the market leader. Product differentiation occurs when producers attempt to use the unique qualities of products to sway consumer preference over rival products. Where quality signals are less observable, consumers may become less quality sensitive and more price responsive, leading to suboptimal market performance (Akerlof 1970). In health care markets, the asymmetric information relationship is one where buyers rely entirely on providers for their consumption choices. This kind of relationship is often exploited by the providers to create and sustain a "supplier induced demand," which potential can undermine market outcomes (McPake and Normand 2013).

Usually, the interplay of structural and conduct components of a market together generate the nature of competition that characterizes it and defines its performance and indirectly social welfare. Markets have structurally been classified into 4 broad groups based on market concentration and power to influence price. These represent perfect competition, monopoly, monopolistic competition and oligopoly market structures. Perfect competition reflects a market with very large number of sellers (un-concentrated structure), with no seller or buyer having influence over quantity of products produced and their price. This being because all sellers are assumed to sell identical (undifferentiated) goods and services and as such, do not compete on the basis of price, but all must follow market price determined by demand and supply. Entry and exit barriers are absent and all market actors are believed to have perfect information about the quality and prices of goods and services in the market.This exemplifies the theoretically ideal market structure, without a real world representation. Monopoly market structure has only one supplier or buyer, with absolute power over quantity and price, and described as concentrated. Entry into this market is virtually blocked. Tucked between these two extreme structures are monopolistic and oligopoly structures, which correspond to low-concentrated and high-concentrated markets, respectively. Monopolistic competition diverges from perfect competition by having differentiated products, and therefore some price competitiveness, while a few dominant firms characterise oligopolistic markets, with high entry barriers. In terms of social outcomes, the S-C-P paradigm predicts that perfect competition would generate the most desirable outcomes, while a monopoly structures will result in least social welfare. The imperfect structures would generate middle-course outcomes (Clark 1985; Tirole 1985; Varian 2006)

Like regular markets, healthcare markets are expected to allocate societal resources most efficiently (Wells et al., 2007), but in the same way conventional markets may fail to deliver optimal outcomes, healthcare services production and distribution poses particularly challenging problems for the market mechanism. Although healthcare markets display a range of peculiar distortionary properties such as concentration, entry barriers, notfor-profit intention, consumer non-sovereignty and externalities, the structure-conduct-performance paradigm remains a useful framework for analyzing health care markets (Detsky 1978; Gaynor and Townsend 2012). The framework provides the basis for understanding the nature of competition in the market: the object of competition, competitive strategies and the intensity of competition, and prediction of market outcomes. Understanding these relationships will guide the development of the means and ways of improving health market performances through appropriate policies.

\section{Methods}

The study was conducted at Katsina-Ala Local Government Council of Benue State, north central Nigeria from January to September, 2015. The local council is rural with a population of 249, 219, most of whom are farmers. It has 93 patent medicine vendor outlets strewn across its length and breadth, one general hospital and 47 primary health centres. The patent medicine vendor association in the council was organized into 5 geographical markets 
namely, Katsina-Ala township, Sai, Gbor, Abaji and Tor Donga sub-markets.

A mixed method design was used in the study, deploying questionnaires and in-depth interviews tools to collect data. A random sample of 30 patent medicine vendors was taken and asked to complete structured questionnaires in relation to socio-demographic characteristics, market structure and regulatory enforcement and compliance. A further 10 most enthusiastic vendors were purposively picked for in-depth interviews to critically examine retailers' self-perceptions about market conduct and performance. Similarly, the same numbers of patent medicine vendor outlet clients were systematically surveyed and interviewed. Interviews were digitally recorded in English and in the native language for non-English speaking consumers, with the latter back translated into English.

Qualitative interviews were transcribed and the transcription notes reviewed for accuracy. The contents were then carefully re-read and manually coded line by line into structured categories, guided by apriori codes generated based on the purpose of the study. Quantitative data was analyzed using statistical package for social sciences (SPSS) version 20.0. Market concentration estimation was undertaken along the five geographical markets of the association of patent and proprietary medicine vendors of Nigeria, Katsina-Ala branch, and then over the monolithic market. The inverse Herfindahl Hirschman Index (HHI) was used to measure concentration as against the standard HHI because an audit of products sold in this market was not undertaken due to time constraint and over $80 \%$ of surveyed retailers did not report their gross annual sales turn-over. Patent medicine vendor shop per capita was calculated to understand the pattern of access to pharmaceuticals.

Ethical approval to for the study was obtained from the Benue State Government, Nigeria and Queen Margaret University, Edinburgh Participants were enrolled into the study after oral consent, and anonymity and confidentiality of the information collected was ensured.

\section{Results}

Sellers in this market were small sized, selling branded and generic drugs, with none capable of setting the price of any product. In terms of entry barriers, since most of the firms are small, they did not have advantages of economies of scale and the capital requirements for market entry were not huge enough to pose a barrier. Consumers could easily switch from one seller to another without incurring much cost.

\section{Market Concentration}

The overall inverse Herfindahl-Hirschman Index was estimated at 0.01, meaning the market is low concentrated on aggregate and implies a competitive market structure. However, at the sub-market level, all sub-markets were concentrated except Kastina Ala township sub-market. Using patent medicine shop as proxy for a pharmacy, and based on the WHO standard of one pharmacy to 2000 population (Azhar et al. 2009), again, only the Katsina-Ala sub-market met the requirement for adequate population access to essential drugs with a drug outlet per capita of 1:1,168. However, overall, the market provided one drug shop to 2,669 populations, which failed to provide adequate access, meaning that there were fewer sellers in the market than is required to guarantee adequate access to medicines. These findings are presented in Table 1 below:

Table 1: Market Concentration and Access in Katsina-Ala Local Government Council

\begin{tabular}{lllll}
\hline District & Nos. shops & Population & Shop per pop. & Inverse HHI $(1 / \mathrm{N})$ \\
\hline Abaji & 8 & 36,735 & $1: 4,591$ & 0.125 \\
Gbor & 12 & 43,180 & $1: 3,598$ & 0.083 \\
Katsina-Ala & 56 & 65,423 & $1: 1,168$ & 0.018 \\
Sai & 5 & 55,835 & $1: 11,167$ & 0.2 \\
Tor Donga & 12 & 47,045 & $1: 3,920$ & 0.083 \\
\hline
\end{tabular}

$\mathrm{N}=$ number of shops in a sub-market

An estimated inverse HHI of 0.01 for the entire market implies unconcentrated market, but the corresponding finding of one drug shop to 2,669 populations means inadequate access. These findings challenge the sufficiency of focusing on market concentration measure in health care market regulation as an unconcentrated health care market may not necessarily guarantee desirable access to health care services by consumers.

\section{Entry Barriers}

A number of factors were found to constitute entry barriers in the market. The technical nature of drugs underscored prior knowledge of drugs as a requirement for entry into the patent medicine market as noted by a participnat:

"You cannot do patent medicine business without training in the business. It is not like provision selling, where anybody can just decide today to start buying and selling and he start." (R 07)

Further, the collectivisation and coordination of sellers under the national association of patent and proprietary medicine dealers (NAPPMED) also portended covert entry barrier into the market as this response implied:

"If our union finds any person who is selling without being a member of the union, we ask them to get registered, 
and if they fail to do so, we do ask police to go and pounce on them." (R 09)

These entry barriers notwithstanding, the majority of providers believed entry by new entrants into the business was free, meaning that entry barriers into the market are low broadly.

\section{Horizontal and Vertical Linkages}

Evidence of horizontal linkages existed in the market. It was found that over $70 \%$ of interviewed retailers entered the market through mentorship model whereby, an apprentice understudies an experienced vendor over a tie-in period, and proceeds to establish a self owned drug shop. This mode of entering the business sets up an allegiancetype relationships and covert horizontal affiliations. During the study, a few respondents would not complete the questionnaire until permitted by their mentors. There was no evidence of vertical linkages as retailers were found to stock from multiple sources, with majority (53\%) using pharmacies while $35 \%$ stocked through wholesalers.

\section{Provider Conduct}

Although patent medicine vendors perceived themselves as expert custodians of pharmaceuticals and drug consumers as inadequately informed about drugs, consumer sovereignty was fully recognised and drugs were dispensed freely on demand. A transaction failed only in situations where a vendor was stocked out. The free exercise of choice by consumers and providers passively responding to demand resulted in the sale of inappropriate doses of medications on some occasions.

\section{Pricing and price mark-ups}

Price traditionally serves as the pivot of market analysis, as this understanding is key in defining the nature of competition. This is particularly important in this study given the context of poverty, combined with full out of pocket payments.

The pricing of drugs in the market was determined by drug costs, informal payments to public officials, transportation costs and profit mark-up. The role of a dominant price leader appeared insignificant, and identical medicines sold for uniform prices across all outlets. The market was said to be small for differential pricing without losing custom:

"They will run away if I say a card of ampiclox is NGN 150.00 , when everybody knows is NGN 80.00." (R 05) On price mark-ups, one respondent said:

"In the area of this field of medicine, there are some drugs you bought and then, even if you sell cheaper, you will be topping $50 \%$ to $100 \%$ of what you bought." (R 06)

Uniform pricing in an imperfect market, without a market leader might suggest collusive practices.

\section{Regulation and Regulatory Compliance}

Patent and proprietary medicine vendors are licensed to stock and sell simple over-the-counter medicines only (PCN 2003), but they transacted in prescription only drugs and medical consumables as well. They also consulted and prescribed, all in breach of their legal remits. This was encapsulated in this response:

"..., it is because of ignorance and the lack of adequate regulations and adherence to the laws that is actually perpetrating these practices" (R09)

Regulatory officials were equally aware of the predilection of patent medicine vendors for regulatory infractions and abuse of their practice limits:

"If you go out to their shops, you will be seeing it oh. They hide the prescription drugs in some places, and when you request, they will take it from the carton. They are not supposed to do wholesaling, but certain vendors are involved in wholesaling".

All medicine vendors studied while agreeing to the critical need for regulation to mitigate harm against the population, cited the absence of alternative health facilities in the communities they served to justify their conduct, as implicit in this response:

"There are some drugs that really as you said, the government does not allow us to sell, so we sell them to people that we feel we can assist them, since we are the only one they can come to get those drugs and it will help them." (R 06)

The implication of this is that if access to essential medicines that are used to treat illnesses, or that constitute lifesaving therapy are unreasonably restricted, particularly for illnesses affecting people living in rural areas, government should recognize these peculiarities in its regulatory strategies. Otherwise, regulations become unenforceable.

\section{Market Performance Indicators}

The market performance was reflected in a number of concerns bordering on low qualifications of providers who seldom have pharmacy education and incapable of matching specific disease with their appropriate medication. Also decried, was the stocking of counterfeit/sub-standard drugs, or beyond permitted remits. 


\section{Drug quality}

Drug consumers expressed concerns about the quality of drugs bought from patent medicine vendors' outlets, which were sometimes said to either be ineffective, caused adverse effects, or fake, as attested by these views:

"Some of them sell fake drugs, such that even if you take it, it will not work." (R 08)

"Yeah, for quality, I cannot bet on that, but the quality when you buy from the pharmacy, is better than retail shops." (R 08)

\section{Affordability of drugs}

Relative affordability of drug cost was the most frequent motivation for the use of patent medicine vendor shop compared to other formal outlets:

"Some people may not afford the money to go to the hospital, you can see that even the little here they find it difficult to afford, how much more will they afford that of the hospitals?" (R 09)

"Personally, my treatments are mostly done in government hospital, it is because of financial constraints that have made me come to a retail shop for treatment." (R 06)

\section{Drug availability}

It further emerged that drug consumers found patent vendor shops more reliable and dependable sources of needed drugs compared to hospitals that almost always experienced drug stock out.

"The difference there is, when I go to the hospital, they always don't have drugs for me, so I come to the retail shops and buy." (R 03)

In sum, although patent medicine outlets improved affordability and availability, the market is fraught with perverse regulatory infractions, poorly trained providers, and poor quality of drugs at high costs.

\section{Discussion}

Overall, this market is low concentrated, implying competitiveness and associated socially desirable outcome. This is compatible with the findings of Jerome and Ogunkola (2000) that retail markets in Africa are generally unconcentrated, but contrasts the concentrated structure of the retail market of malarial fever in Tanzania (Goodman 2004). Whilst the unconcentrated nature predicts a socially optimal performance of the market, the measure of shop per capita, showed inadequate access to drug outlets for consumers. This contradiction underscores the weakness of market concentration as a measure of efficiency in healthcare markets. Therefore, in health markets, unconcentration alone is an insufficient indicator of market performance. Measures of access may better estimate performance in healthcare markets, rather than some quantified statistical ideal.

The study also found that the population of patent medicine vendor shops declined and the market more concentrated as one moved out of Katsina-Ala township, the economic and administrative headquarters of the local council. Doucette and colleagues (1999) also found more retail pharmacies per capita in U.S. counties with higher per capita incomes, while counties with high poverty rates had lower pharmacies per capita.

There were low entry and exit barriers, which supports the finding of Jerome and Ogunkola (2000), who characterised retailing as highly diverse and dynamic, changing considerably with political, economic, social and environmental forces. The authors also showed that entry barriers into retail markets are few with minimal technical constraints. However, appropriate therapeutic uses of pharmaceuticals require high technical skills.

From the consumer perspective, a price top-up of $50 \%$ to $100 \%$ established in the study is high when benchmarked against international standards. WHO, recommends mark-ups of between $25-50 \%$ on retail pharmaceuticals (WHO/HAI 2011), and also when compared to the US where gross retail mark-ups have only averaged $25 \%$ for most of the $20^{\text {th }}$ Century (Larson and Rosen 2002; Kaiser Family foundation 2005). Price markups in retail markets are said to be high and vary widely across outlet type, location and product characteristics (Goodman et al. 2009), oscillating between 29\% to 669\% in drug shops (Clinton Foundation 2008).Unofficial practices and regulatory capture in African health care markets have been widely reported, and positively correlated with retail price mark-ups (McPake et al. 1999; Russo and McPake 2009; Wafula, et al. 2013).

Theory predicts that retail prices should be a sensitive indicator of pricing behavior, so the uniform price levels of similar drugs in the market may be understood form the abstraction of kinked demand curve, or collusive oligopoly (Clarke 1985). The Kinked demand model posits that if sellers believed that a price cut will be matched, but not a price rise, then prices will remain sticky. This provides a lens to see why no seller in the market might have attempted to vary their prices. Furthermore, tacit collusive pricing might also have resulted in the price behavior observed. The unionisation of sellers (NAPPMED) would have ensured that members conformed to union decision that discouraged competitive individualism. Additionally, the low elasticity of demand associated with healthcare and the must-have nature of pharmaceuticals, lack of alternatives in these remote areas may also account for the high prices found.

Regulatory approaches in this market were based on the traditional bureaucratic and administrative practice of registration and licensing of practitioners, drugs and business premises, while implementation and compliance 
remained weak. This approach was found to fail to match demand and supply of drugs in the market appropriately, hence the practice of sellers stocking beyond their legal remit.

From the analysis, the patent medicine market exhibits both competitive and monopoly features. Though the retailers sold an array of drugs, within a drug category, these were reasonably homogenous products, because they contained the same chemical compound. No attempts by individual retailers to influence market structure through publicity strategies or price manipulation. Buyers obtained drugs freely and also had options to freely choose where they made purchases. These features place the market in the competitive domain. However, entry is constrained by regulatory requirements and the implicit collusive influence of the union of retailers, on price. This sort of cooperative market behaviour among micro-enterprise owners, rather than competition, has been documented in reviews of industrial structure and microenterprise in Africa (Fafchamps 1994; Tripp 2001). Furthermore, retailers exhibited strategic pricing behaviour by taking into account the expected behaviour of their competitors, particularly in the situation of upward price change. These characteristics are consistent with oligopolistic competition.

\section{Conclusion}

The overall market concentration reflects an unconcentrated structure, but the individual geographical markets exhibit a plural structure consisting of monopolistic and oligopolistic features. This market structure is marked by reduced competitive rigor and outcomes, as seen in the high mark-up of drugs. The drug shop per capita reflects inadequate access despite an overall unconcentration inverse Herfindahl-Hirschman Index. We therefore, argue that focusing on economic efficiency oriented regulations of health care markets may not result in the attainment of the health system goal of adequate access to health care. Government regulatory bodies should incorporate proaccess enhancing strategies along with competition policies to better discipline health care markets in order to achieve desired market performance.

Acknowledgement: This publication was made possible through the training support received from STAMINA, University of Jos, Nigeria.

\section{References}

1. ACTwatch. 2013. Nigeria 2013 outlet survey results. [Online]. Available at: http://www.actwatch.info. [Accessed January 26 2015].

2. Adikwu, M. U. 1996. Sales practices of patent medicine sellers in Nigeria.Health policy and planning, 11 (2), pp. 202-220.

3. Alubo, O. 2001. The promise and limits of private medicine: health policy dilemmas in Nigeria. Health policy and planning, 16 (3) pp. 313-321.

4. Akerlof, G. 1970. The market for lemons: Quality uncertainty and the market mechanism. Quarterly Journal of Economics, 84 (3) pp. 488-500.

5. Azhar, S., Hassali, A.M., Ibrahim, I. M. M., Ahmad, M., Masood, I. and Shafie, A. A. 2009. The role of pharmacists in developing countries: the current scenario in Pakistan. [Online].Available at: http://www.human-resources-health.com/content/ Accessed November 202013.

6. Brieger, R. W., Osamor, P., Salami, K. K., Oladepo, O. and Otusanya, A. 2004.Interactions between patent medicine vendors and customers in urban and rural Nigeria.Health Policy and Planning, 19 (3) pp. 177-182.

7. Clarke, R. 1985. Industrial Economics. Massachusetts: Blackwell Publishers Inc.

8. Clinton Foundation. 2008. Review of private sector antimalarial market in Tanzania.

9. Detsky, A. S. 1978. The Economic Foundations of National Health Policy. Cambridge, MA: Ballinger Publishing Co.

10. Doucette, W. R., Brooks, J. M., Sorofman, B. A. and Wong, H. S. 1999.Market factors and the availability of community pharmacies. Clinical Therapeutics, 21 (7) pp. 1267-1279.

11. Djankov, S., La Porta, R. Lopez-de-Silanes, R. and Shleifer, A. 2002.The regulation of entry.The Quarterly Journal of Economics, 117 pp. 1-37.

12. Encaoua, D. and Jacquemin, A. 1980.Degree of Monopoly, Indices of Concentration and Threat of Entry. International Economic Review, 21 pp. 87-105.

13. Fafchamps, M. 1994. Industrial structure and microenterprises in Africa. The Journal of Development Areas, 29 pp.1-30.

14. Gaynor, M. and Town, J. R. 2012.Competition in Health Markets.Centre for Market and Public Organization Working Paper Series Nos. 12/282.

15. Gaynor, M. and Vogt. B. 2000. Antitrust and Competition in Health Care Markets. In: Culyer, J. A. and Newhouse (eds.). Handbook of Health Economics.Elsevier Science B. V.

16. Goodman, C., Kachur, S. P., Abdulla, S., Mwageni, E., Nyoni, J., Schellenberg, A. J., Mills, A. and Bloland, P. 2004. Retail supply of malaria-related drugs in rural Tanzania: risks and opportunities. Tropical Medicine and International Health, 9 (6) pp. 655-663. 
17. Goodman, C., Kachur, S. P., Abdulla, S., Bloland, P. and Mills, A. 2009.Concentration and drug prices in the retail market for malaria treatment in rural Tanzania. Health Econ, 18 pp. 727-742.

18. Jerome, A. and Ogunkola, O. 2000.The characteristics and behaviour of African commodity/product market institutions and their consequences for economic growth. CID Working Paper No. 35.

19. Kaiser Family Foundation. 2005. Follow the pill: understanding the US commercial pharmaceutical supply chain. [Online].Available at: http://www.kff.org/rxdrugs/upload[Accessed February 082018 ].

20. Larson, A. B. and Rosen, S. 2002. The retail market for bed nets in Kenya: How well is it working? Health and Development Discussion Paper No. 2. Boston, MA: Centre for International Health, Boston University of School of Public Health.

21. McPake, B., Asiime, D., Mwesigye, F., Ofumbi, M., Ortenblad, L., Srreetfland, P., and Turinde, A. 1999. Informal economic activities of public health workers in Uganda: implications for quality and accessibility of care. Social Sciences and Medicine, 49 pp. 849-865.

22. McPake, B. and Normand, C. 2013. Health Economics: An International Perspective. $2^{\text {nd }}$ ed. London and New York: Routledge.

23. National Population Commission and ICF Macro. 2009. Nigerian Demographic and Health Survey: Key Findings. Calverton, Maryland: NPC and ICF Macro.

24. Nelson, P. 1970. Information and consumer behaviour. Journal of Political Economy, 78 pp. 311-329.

25. Oladepo, O., Salami, K. K., Adeoye, B. W., Oshiname, F., Ofi, B., Oladepo, M., Ogunbemi, O., Lawal, A., Brieger, W. R., Bloom, G. and Peters, F. H. 2007.Malaria treatment and policy in three regions in Nigeria: the role of patent medicine vendors. Future health systems working paper 1 Nigeria series. [Online].Available at: http://www.futurehealthsystems.org [Accessed September 19 2018].

26. Pharmacists Council of Nigeria (PCN). 2003. Guidelines on the issuance of patent and proprietary medicines vendor's licence. Abuja: PCN.

27. Russso, G. and McPake, B. 2010. Medicine prices in urban Mozambique: a public health and economic study of pharmaceutical markets and price determinants in low-income settings. Health Policy and Planning.25 pp. 70-84.

28. Salako, L. A., Brieger, W. R., Afolabi, B. M., Umeh, R. E., Agomo, P. U., Asa, S., Adeneye, A. K., Nwakwo, B. O. and Akinlade, C. O. 2001. Treatment of childhood fevers and other illnesses in three rural Nigerian communities. J Trop Pediatr.47 pp. 230-238.

29. Tirole, J. 1988. The theory of Industrial Organization. Cambridge, Massachusetts: The MIT Press

30. Tripp, A. M. 2001. Non-formal institutions, informal economies and the politics of inclusion. World Institute for Development Economic Research Discussion Paper No. 2001/108.

31. UN. 2019. Universal health coverage for sustainable development: Issue brief. New York: United Nations Development Programme

32. UN. 2000. We the peoples: the role of the United Nations in the Twenty-First Century. The Millennium Report 2000. New York: United Nations.

33. UNCTAD 2015 Seventh United Nations Conference to Review All Aspects of the Set of Multilaterally Agreed Equitable Principles and Rules for the Control of Restrictive Business Practices Geneva, 6-10 July 2015

34. Usar, J. I., Witter, S., McPake, B. (2017). Universal Health Coverage in Nigeria: Strategies for engagement of patent medicine vendors in rural communities. Highland Medical Research Journal, 17(2), 86-91.

35. Varian, H. R. 2006.Intermediate Economics. $6^{\text {th }}$ ed. New York: W, W. Norton and Company Inc.

36. Wafula, F., Molyneux, C., Mackintosh, M. and Goodman, C. 2013. Protecting the public or setting the bar too high? Understanding the causes and consequences of regulatiry actions of front-line regulators and specialized drug shops in Kenya.Social Science and Medicine, 97(2013) pp. 220-227.

37. Wells, D. A., Ross, J. S. and Detsy, A. S. 2007. What is Different about the Market for Health Care? JAMA, 298 (23) pp. 2785-2787.

38. WHO 2014. Making fair choices on the path of universal health coverage. Final report of the WHO Consultative Group on Equity and Universal Health Coverage. Geneva: WHO.

39. WHO. 2013 World Health Organization. 2013. Research for universal health coverage. Geneva: WHO.

40. World Health Organization and Health Action International (WHO/HAI). 2003. Medicine Prices: a new approach to measurement Illustrative examples of results from pilot studies, 2001-2002. Geneva: WHO/HAI. 